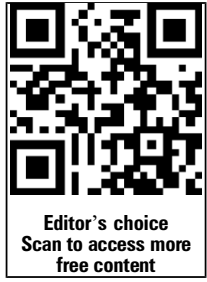

free content

\title{
Hamstring injuries have increased by $4 \%$ annually in men's professional football, since 2001: a 13-year Iongitudinal analysis of the UEFA Elite Club injury study
}

\author{
Jan Ekstrand, ${ }^{1,2,3}$ Markus Waldén, 1,2 Martin Hägglund ${ }^{2,4}$
}

\begin{abstract}
${ }^{1}$ Division of Community Medicine, Department of Medical and Health Sciences, Linköping University, Linköping, Sweden ${ }^{2}$ Football Research Group, Linköping, Sweden ${ }^{3}$ UEFA Medical Committee, Nyon, Switzerland ${ }^{4}$ Division of Physiotherapy, Department of Medical and Health Sciences, Linköping University, Linköping, Sweden
\end{abstract}

\section{Correspondence to}

Professor Jan Ekstrand, Division of Community Medicine, Department of Medical and Health Sciences, Linköping University, Hertig Karlsgatan 13B, Linköping S-582 21, Sweden;

jan.ekstrand@telia.com

Accepted 11 December 2015 Published Online First 8 January 2016

\section{SLinked}

- http://dx.doi.org/10.1136/ bjsports-2015-095952

\section{CrossMark}

\author{
To cite: Ekstrand J, \\ Waldén $\mathrm{M}$, Hägglund $\mathrm{M}$. $\mathrm{Br}$ \\ J Sports Med 2016;50
}

731-737.

\begin{abstract}
Background There are limited data on hamstring injury rates over time in football.

Aim To analyse time trends in hamstring injury rates in male professional footballers over 13 consecutive seasons and to distinguish the relative contribution of training and match injuries.

Methods 36 clubs from 12 European countries were followed between 2001 and 2014. Team medical staff recorded individual player exposure and time-loss injuries. Injuries per $1000 \mathrm{~h}$ were compared as a rate ratio (RR) with $95 \% \mathrm{Cl}$. Injury burden was the number of lay off days per $1000 \mathrm{~h}$. Seasonal trend for injury was analysed using linear regression.

Results A total of 1614 hamstring injuries were recorded; $22 \%$ of players sustained at least one hamstring injury during a season. The overall hamstring injury rate over the 13-year period was 1.20 injuries per $1000 \mathrm{~h}$; the match injury rate (4.77) being 9 times higher than the training injury rate $(0.51$; RR 9.4; $95 \%$ $\mathrm{Cl} 8.5$ to 10.4). The time-trend analysis showed an annual average $2.3 \%$ year on year increase in the total hamstring injury rate over the 13-year period $\left(R^{2}=0.431\right.$, $b=0.023,95 \% \mathrm{Cl} 0.006$ to $0.041, p=0.015)$. This increase over time was most pronounced for training injuries - these increased by $4.0 \%$ per year $\left(R^{2}=0.450\right.$, $b=0.040,95 \% \mathrm{Cl} 0.011$ to $0.070, p=0.012$ ). The average hamstring injury burden was 19.7 days per $1000 \mathrm{~h}$ (annual average increase $4.1 \%)\left(R^{2}=0.437\right.$, $b=0.041,95 \% \mathrm{Cl} 0.010$ to $0.072, p=0.014$ ).

Conclusions Training-related hamstring injury rates have increased substantially since 2001 but matchrelated injury rates have remained stable. The challenge is for clubs to reduce training-related hamstring injury rates without impairing match performance.
\end{abstract}

\section{INTRODUCTION}

Muscle injuries are a substantial problem for professional football players. They constitute more than one-third of all time-loss injuries and cause more than a quarter of the total injury absence in high-level European professional football clubs. ${ }^{1}$ Hamstring injury is the most common injury subtype, representing $12 \%$ of all injuries, and a team with a 25 player-squad typically suffers about 5-6 hamstring injuries each season, equivalent to more than 80 days involving football activities (training or matches) lost due to injury. ${ }^{1}$

The overall burden of muscle injuries could be very significant for professional football clubs. ${ }^{2} 3$ The average cost of a first-team player in a professional team being injured for 1 month is calculated to be around $€ 500000 .{ }^{4}$ Eccentric muscle strength training has been promoted as a method to prevent hamstring injuries. ${ }^{5-10}$ In a randomised controlled trial (RCT), eccentric training with the 'Nordic hamstring (NH) exercise' significantly decreased the rate of hamstring injuries in Danish elite, subelite and amateur players, ${ }^{8}$ and in Dutch amateur players. ${ }^{9}$ However, adoption and implementation of the $\mathrm{NH}$ exercise programme in men's professional football in Europe is low, too low to expect any overall effect on hamstring injury rates from. ${ }^{11}$

In male professional football players, the muscle injury rate has remained high and unchanged for more than a decade. ${ }^{12}$ It is, however, unclear from that study whether this is also true for the main subgroups of muscle injuries. To the best of our knowledge, the development of hamstring injuries over time in football has not been investigated before. The objective of this study was therefore to describe the time trend in hamstring injury rate in men's professional football in Europe over 13 consecutive seasons, and to distinguish the relative contribution of training and match injuries.

Our hypothesis was that the hamstring injury rate, similar to the overall muscle injury rate, would remain constant.

\section{MATERIAL AND METHODS}

This is a substudy of a long-term prospective cohort study evaluating male professional football in Europe funded by the UEFA. A total of 36 clubs from 12 countries were followed over a varying number of seasons from 2001 to 2014, with a total of 209 club-seasons included. The study design adhered to the consensus statement on injury definitions and data collection procedures in football, ${ }^{13}$ and the general methodology has been reported elsewhere. ${ }^{14}$

\section{Inclusion criteria and definitions}

All players belonging to the first-team squads each season were eligible for inclusion. Players who were transferred to other clubs or who finished their contracts due to other reasons before the end of a season were included for as long as they played for the club. Only players who were contracted to the club for at least half the season ( $\geq 5$ months) were included in this substudy, since having many players with exposure for only a month or two would skew the prevalence figures as well as the exposure 
per player-season data. Totally, 5216 player-seasons were included for analysis. The general operational definitions are listed in table 1 . Hamstring injury was defined as a traumatic distraction or overuse injury to the hamstring muscle group (the musculotendinous complex of biceps femoris, semitendinosus and semimembranosus), including both first-time and recurrent injuries. Players were considered injured until the club medical staff (medical doctor or physiotherapist) allowed full participation in training and availability for match selection.

\section{Data collection}

An instructive study manual and study forms were translated by experienced translators within UEFA from English into five other languages: French, German, Italian, Russian and Spanish. Baseline player data and consent were collected once yearly at the time of player inclusion. During the season, a member of the medical or coaching staff registered individual player exposure in minutes during all club (first-team, second-team or youthteam) and national-team training sessions and matches. Injury and attendance reports were sent to the study group once a month. Reports were checked on receipt by the study group and prompt feedback was sent to the teams in order to correct any missing or unclear data. Each injury was coded according to a modified version of the Orchard Sports Injury Classification System (OSICS) 2.0. ${ }^{15}$

\section{Statistical analyses}

Lay off times are presented as mean \pm SD and median with 25 th and 75 th centiles. Injury rate was calculated as the number of injuries per $1000 \mathrm{~h}$ with corresponding 95\% CI. Injury rates were compared using a rate ratio (RR) with 95\% CI. Injury burden was calculated as the number of lay off days per $1000 \mathrm{~h}$ (injury rate $\times$ mean absence per injury). Seasonal trend for hamstring injury rate and injury burden, expressed as average annual percentage of change, was analysed using linear regression with

\begin{tabular}{|c|c|}
\hline Training session & $\begin{array}{l}\text { Team training that involved physical activity under the } \\
\text { supervision of the coaching staff }\end{array}$ \\
\hline Match & Competitive or friendly match against another team \\
\hline Injury & $\begin{array}{l}\text { Any physical complaint sustained by a player that resulted } \\
\text { from a football match or football training and led to the } \\
\text { player being unable to take a full part in future football } \\
\text { training or match play }\end{array}$ \\
\hline $\begin{array}{l}\text { Slight/minimal } \\
\text { injury }\end{array}$ & Injury causing $0-3$ days lay off \\
\hline Mild injury & Injury causing 4-7 days lay off \\
\hline Moderate injury & Injury causing 8-28 days lay off \\
\hline Severe injury & Injury causing $>28$ days lay off \\
\hline Traumatic injury & Injury with sudden onset and known cause \\
\hline Overuse injury & Injury with insidious onset and no known trauma \\
\hline Hamstring injury & $\begin{array}{l}\text { A traumatic distraction or overuse injury to the hamstring } \\
\text { muscle group (the musculotendinous complex of biceps } \\
\text { femoris, semitendinosus and semimembranosus) }\end{array}$ \\
\hline Reinjury & $\begin{array}{l}\text { Injury of the same type and at the same site as an index } \\
\text { injury occurring within } 2 \text { months after return to full } \\
\text { participation from the index injury (ie, early recurrent injury) }\end{array}$ \\
\hline $\begin{array}{l}\text { Injury } \\
\text { prevalence }\end{array}$ & $\begin{array}{l}\text { The proportion of players affected by at least one injury } \\
\text { during a season }\end{array}$ \\
\hline Injury rate & $\begin{array}{l}\text { Number of injuries per } 1000 \text { player-hours }((\Sigma \text { injuries } / \Sigma \\
\text { exposure-hours }) \times 1000)\end{array}$ \\
\hline Injury burden & $\begin{array}{l}\text { Number of lay off days per } 1000 \text { player-hours ( }(\Sigma \text { lay off days/ } \\
\Sigma \text { exposure-hours }) \times 1000)\end{array}$ \\
\hline
\end{tabular}

log-transformed injury rate and injury burdens as the dependent variables. In addition, a 2-year moving average (MA) approach, by summarising two consecutive seasons, was also used as a sensitive analysis in order to smooth out possible large seasonal variations. All analyses were two sided and the significance level was set at $\mathrm{p}<0.05$.

\section{RESULTS}

\section{Hamstring injury pattern}

There were 1614 hamstring injuries over the 13-year study period, $564(35 \%)$ of which occurred in training and 1050 $(65 \%)$ in match play. Injury distribution between the legs was even; right leg $50.5 \%$, left leg $49.1 \%$, and bilateral injury occurrence $0.4 \%$. Two-thirds were regarded as acute onset injuries $(n=1060,66 \%)$ and one-third had a gradual onset $(n=554$, $34 \%$ ). Injury distribution according to severity was slight/ minimal $(\mathrm{n}=163,10 \%)$, mild $(\mathrm{n}=339,21 \%)$, moderate $(n=876,54 \%)$ and severe $(n=236,15 \%)$. The number of days lost per injury ranged from 0 to 395 days, with a mean (SD) of 17 (21) days and median (25th, 75th centiles) of $12(6,21)$ days.

\section{Time trends in squad size and exposure}

Time trends in squad size and exposure are shown in table 2. The analyses exhibited an increase in the average squad size per season $(p<0.001)$, and a decline in training exposure per player-season $(\mathrm{p}<0.01)$ as well as in match exposure per playerseason $(p<0.001)$. The ratio of training and matches remained constant over the 13 years of the study.

The analysis did not reveal a significant annual trend of growth or decline in scheduled first-team training sessions with respect to season $\left(\mathrm{R}^{2}=0.0002, \mathrm{~b}=0.039,95 \% \mathrm{CI}(-1.674\right.$ to 1.752), $\mathrm{p}>0.05)$, which was also shown by $\mathrm{MA}$ analysis $\left(\mathrm{R}^{2}=0.011, \mathrm{~b}=0.238,95 \%\right.$ CI $(-1.325$ to 1.800$\left.), \mathrm{p}>0.05\right)$, meaning that the number of scheduled first-team training sessions was approximately the same over the observed time span.

The time-trend analysis of scheduled first-team matches also failed to discern a significant trend in scheduled first-team matches with respect to the season $\left(\mathrm{R}^{2}=0.005, \mathrm{~b}=0.024,95 \%\right.$ CI $(-0.200$ to 0.248$), \mathrm{p}>0.05)$. This conclusion was confirmed by the conducted analysis on MA $\left(\mathrm{R}^{2}=0.001, \mathrm{~b}=-0.005,95 \%\right.$ CI $(-0.155$ to 0.144$), p>0.05)$, which means that the number of matches was approximately equal during the observed period.

\section{Time trends in injury rates and injury burden}

The overall hamstring injury rate over the 13-year period was 1.20 (95\% CI 1.14 to 1.26 ) injuries per $1000 \mathrm{~h}$; the match injury rate being 4.77 (95\% CI 4.49 to 5.06) and the training rate $0.51(95 \%$ CI 0.47 to 0.55$)$ injuries per $1000 \mathrm{~h}$. The match injury rate was nine times higher than the training injury rate (RR 9.4; 95\% CI 8.5 to $10.4, \mathrm{p}<0.001$ ). The time-trend analysis showed an annual average $2.3 \%$ increase in the total hamstring injury rate over the 13 -year period $\left(\mathrm{R}^{2}=0.431, \mathrm{~b}=0.023\right.$, $95 \%$ CI 0.006 to $0.041, \mathrm{p}=0.015)$, with the 2 -year MA approach indicating a $2.2 \%$ yearly increase (figure 1). This increase over time was most pronounced in the training injury rate (figure 2), with a yearly $4.0 \%$ increase $\left(\mathrm{R}^{2}=0.450\right.$, $\mathrm{b}=0.040,95 \%$ CI 0.011 to $0.070, \mathrm{p}=0.012 ; 2$-year MA approach $5.0 \%$ yearly increase), while the match injury rate (figure 3) showed a non-significant $1.5 \%$ yearly increase $\left(\mathrm{R}^{2}=0.225, \mathrm{~b}=0.015,95 \% \mathrm{CI}-0.004\right.$ to $0.034, \mathrm{p}=0.101$; 2-year MA approach $1.1 \%$ yearly increase). 


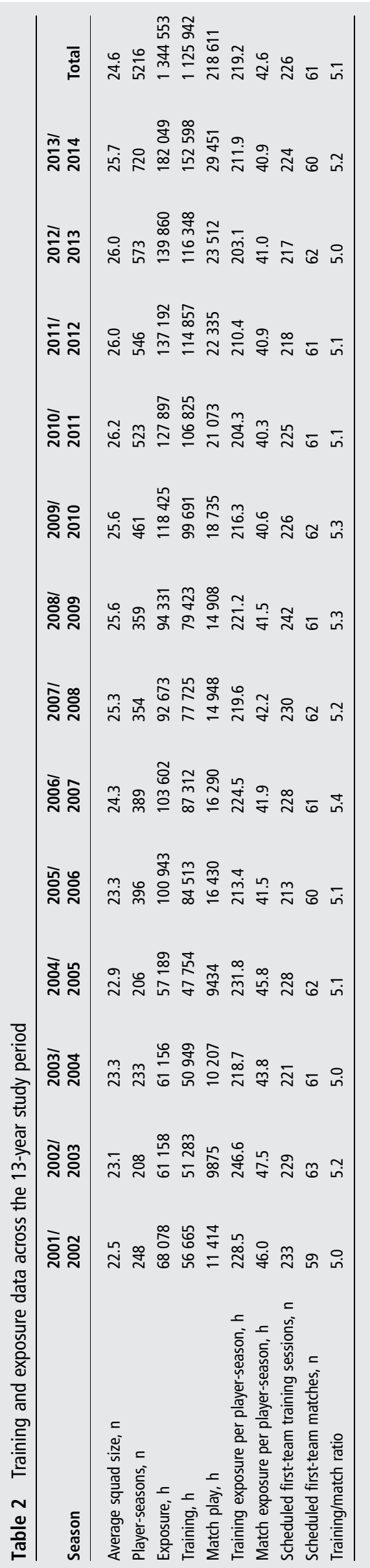

The average injury burden was 19.7 days/1000 h exposure (table 3). Match play was associated with a substantially heavier injury burden than that in training ( 88.5 vs 6.3 injury days absence $/ 1000 \mathrm{~h}$ exposure). Time-trend analysis showed trends similar to those for the injury rates, with an annual average $4.1 \%$ increase in the hamstring injury burden over the 13-year period $\left(\mathrm{R}^{2}=0.437, \mathrm{~b}=0.041,95 \%\right.$ CI 0.010 to 0.072 , $\mathrm{p}=0.014$ ), with the 2-year MA approach indicating a $4.0 \%$ yearly increase (figure 4). A significant $6.4 \%$ annual increase was observed in the training injury burden $\left(\mathrm{R}^{2}=0.506\right.$, $\mathrm{b}=0.064$, 95\% CI 0.022 to $0.107, \mathrm{p}=0.006 ; 2$-year MA approach 9.4\% yearly increase) and a non-significant $3.5 \%$ increase in the match injury burden $\left(\mathrm{R}^{2}=0.256, \mathrm{~b}=0.035,95 \%\right.$ $\mathrm{CI}-0.005$ to $0.074, \mathrm{p}=0.077$; 2-year $\mathrm{MA}$ approach $3.5 \%$ yearly increase).

\section{Injury prevalence and recurrence rates}

On average, $21.8 \%$ of players sustained at least one hamstring injury during a season, with the annual hamstring injury prevalence ranging from $16.8 \%$ to $25.7 \%$ over the 13 -year period (table 3). The average yearly prevalence of hamstring injury occurrence during match play was 15.1\% (range 12.0-17.4\% per season) and, during training, 9.3\% (range 6.7-11.5\% per season). Two-hundred and sixteen injuries (13\%) were recurrences from a previous identical injury within 2 months of return to play. Time-trend analysis of injury rates for index and recurrent injuries separately showed an annual average $2.3 \%$ increase of index hamstring injuries $\left(R^{2}=0.356, b=0.023,95 \%\right.$ CI 0.002 to $0.043, \mathrm{p}=0.031$; 2-year MA approach $2.2 \%$ yearly increase) and a non-significant 3.0\% increase of recurrent injuries $\left(R^{2}=0.218, b=0.030,95 \% C I-0.008\right.$ to $0.068, p=0.108$; 2-year MA approach $5.6 \%$ yearly increase).

\section{DISCUSSION}

Our 13-year (to date) injury surveillance study on men's professional football indicates that the rate of hamstring injuries at training and the injury burden of these injuries have increased significantly since 2001. The incidence of hamstrings injuries at matches has remained stable during the 13 season period.

\section{Why has squad size increased?}

The average first-team squad size has increased in UEFA teams studied-from an average of 23 players during the first 3 years of the study to an average of 26 players during the three latest seasons. ${ }^{12}$ A reason for this increase could be that teams want more players in the squad to rotate players as match congestion can negatively affect team performance and injury risk. ${ }^{16-18}$ Another reason could be that the number of substitutes allowed on the bench at matches has increased in many countries during recent years (the English Premier League have increased the number from 5 to 7 in 2008 and up to 12 substitutes are allowed on the bench in Serie A in Italy). Bigger clubs having the financial capacity to buy more players might also be a reason.

\section{Why has the hamstring injury rate increased during training?}

We have not evaluated the reasons for the observed increase in hamstring injury rates, but we can provide possible explanations. One reason could be that the focus of training sessions included more repeated high-intensity actions that replicate the evolving nature of the game. Many top-level coaches want the training sessions to mirror the demands of a match, with similar intensity and movement patterns. This shift towards repeated high- 


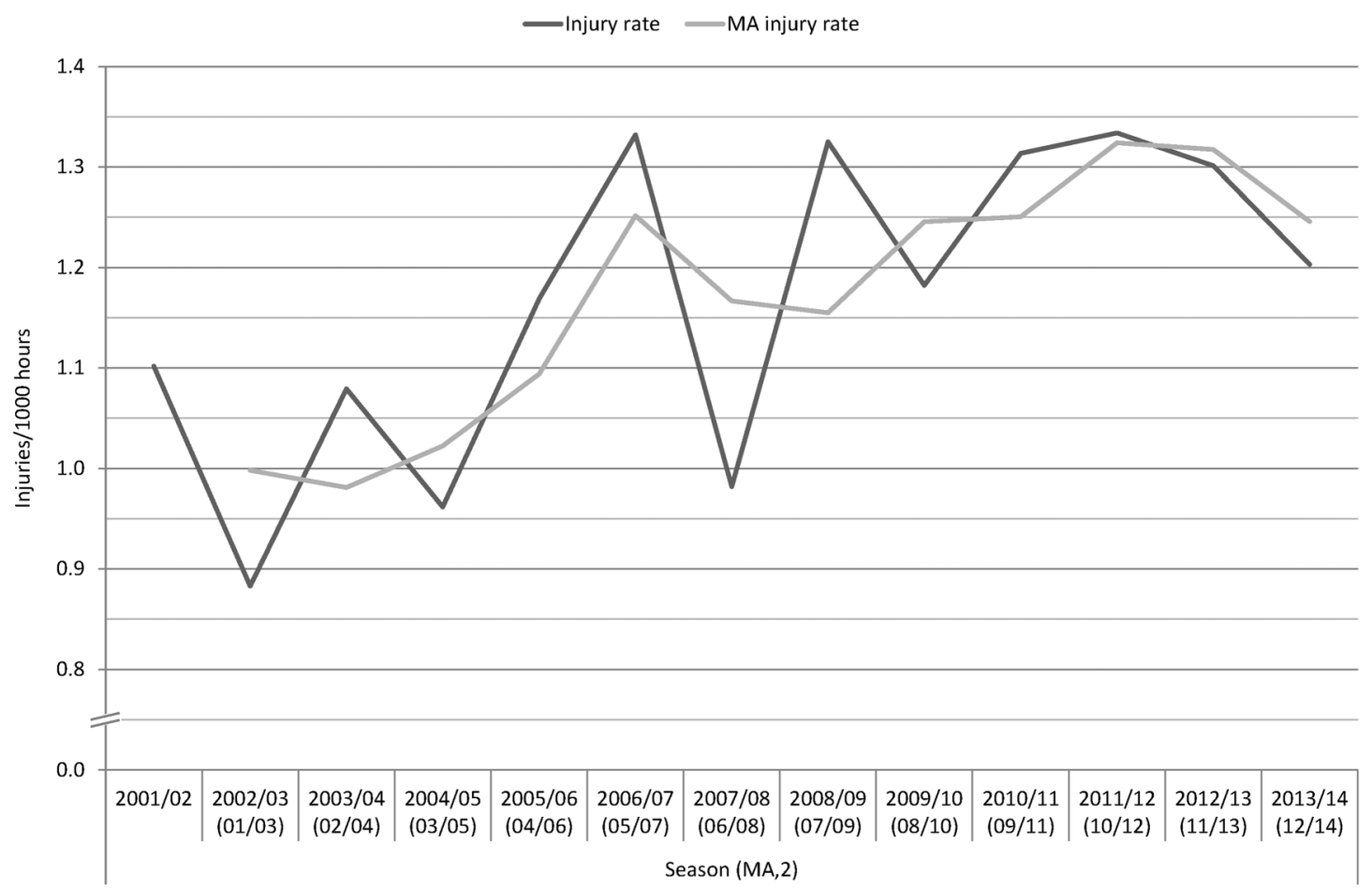

Figure 1 Time-trend analysis in total hamstring injury rates showing a significant annual $2.3 \%$ increase over the 13-year period (black), and the moving average (MA) approach indicating a $2.2 \%$ yearly increase (grey). The $Y$-axis is not proportional.

intensity actions (high-speed running with increased number of accelerations and decelerations) increases the risk of hamstring injuries (the sprinter's injury).

\section{Why has the hamstring injury rate during match play not changed?}

If training sessions are mimicking matches, the players are better prepared for match situations. If there is a deliberate overload stimulus at training, to achieve the desired training effect, this strategy might increase the incidence of training injuries, but, on the other hand, the players who are fit will be better prepared for match intensity, which might reduce the match injury risk. If this tendency continues, the risk of hamstring injuries at matches will slowly be lowered while the risk at trainings will approach the risk at matches.

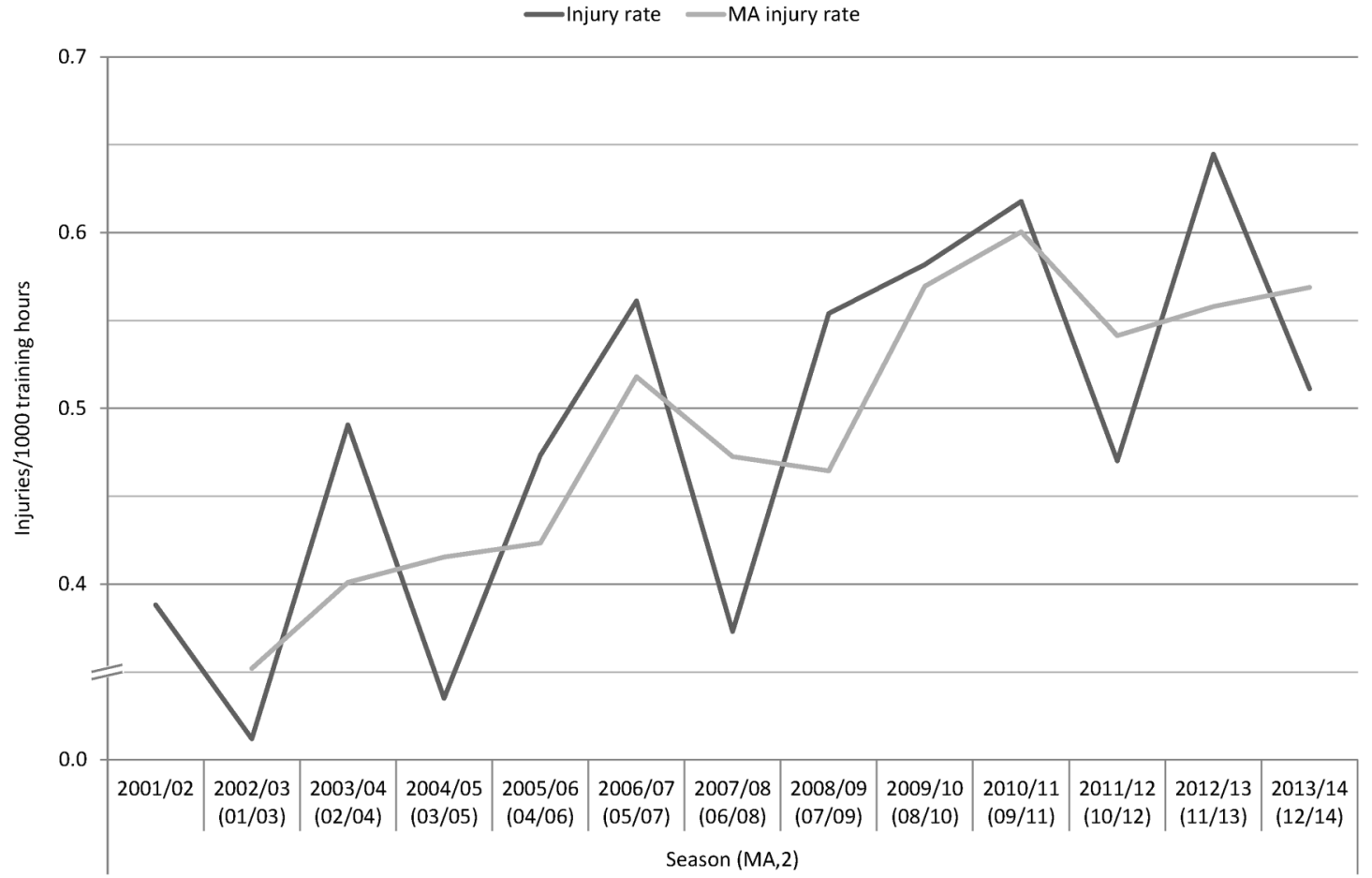

Figure 2 Time-trend analysis in hamstring training injury rates showing a significant annual $4.0 \%$ increase over the 13-year period (black), and the moving average (MA) approach indicating a 5.0\% yearly increase (light grey). The Y-axis is not proportional. 


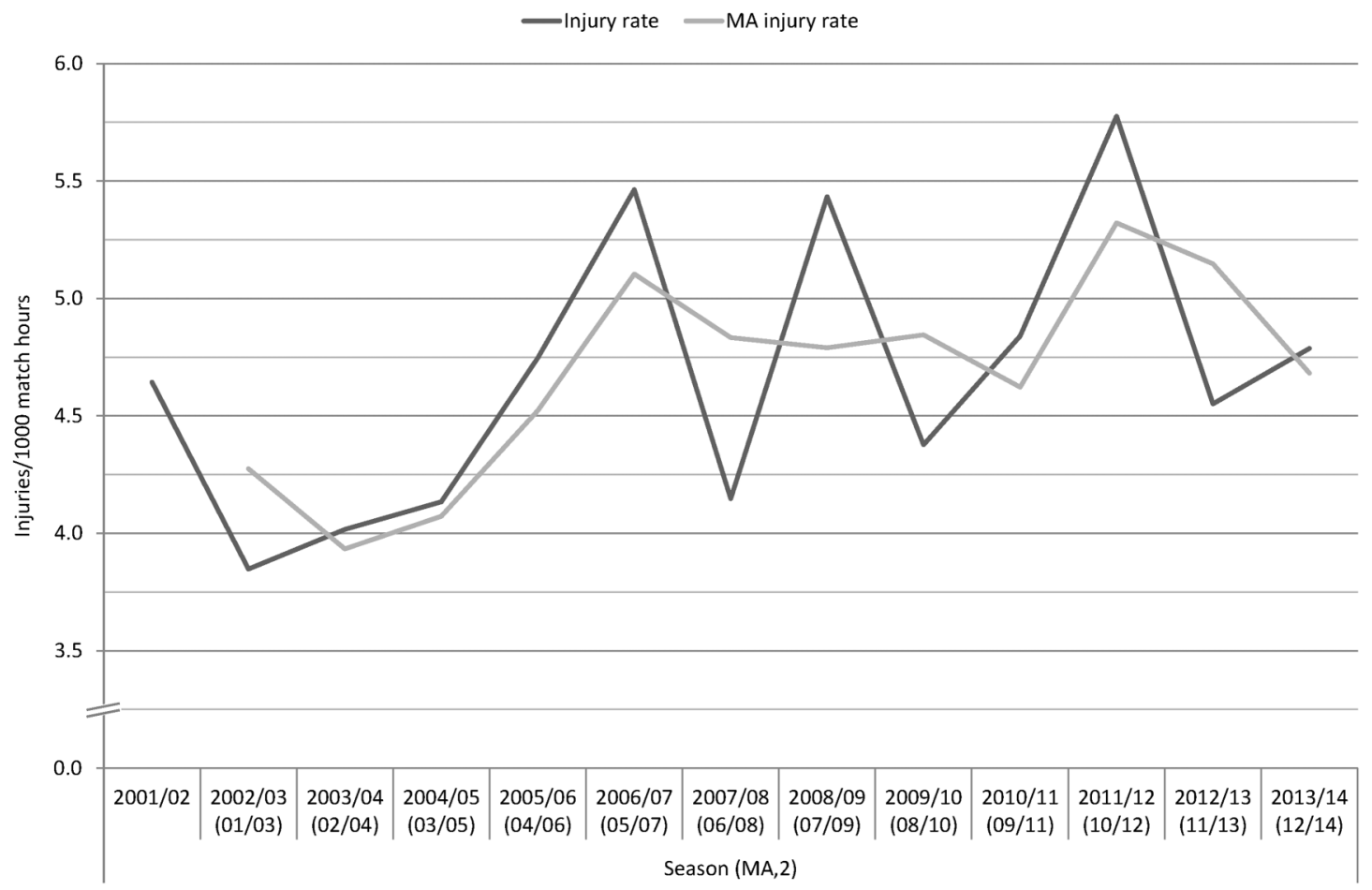

Figure 3 Time-trend analysis in hamstring match injury rates showing a non-significant annual 1.5\% increase over the 13-year period (black), and the moving average (MA) approach indicating a $1.1 \%$ yearly increase (grey). The $\mathrm{Y}$-axis is not proportional.

\section{Why have hamstring injury rates increased when there are well-known evidence-based preventive measures?}

Eccentric muscle actions have been discussed as important mechanisms in the causation of hamstring injuries, ${ }^{7}$ and eccentric resistance training such as the $\mathrm{NH}$ exercise programme has been widely promoted for injury prevention. ${ }^{5-9}$ We were surprised that, in the current study, hamstring injury rate at training and the burden of these injuries increased yearly over the surveillance period, and the hamstring injuries at matches remained at the same high level in spite of the well-known evidence-based preventive measures.

On the other hand, any preventive measures for hamstring injuries could have been counteracted by an increased intensity of the game over the years. For example, Barnes et al ${ }^{19}$ investigated the evolution of physical and technical performance from seasons 2006/2007 to 2012/2013 in the English Premier League, and found a 30\% increase in high-intensity running distance and actions, and a $35 \%$ increase in sprint distance and number of sprints over the years. They also found a significantly higher proportion of explosive sprints during the season 2012/ 2013 compared with 7 years earlier. Consequently, an increase in the hamstring injury rate would be natural if such actions were increased during the play since, as we previously reported, $70 \%$ of hamstring injuries in the UEFA Elite Club Injury Study occurred during sprinting or high-speed running. ${ }^{20}$

\section{The importance of successful implementation of injury prevention measures}

The adoption and implementation of the $\mathrm{NH}$ exercise was very low among the 32 clubs participating in the UEFA Elite Club injury study in the 2014-2015 season; only 5 (16\%) of clubs used the exercise in full. ${ }^{11}$ Although the reach of the $\mathrm{NH}$ exercise was good among the club medical staff (88\% were familiar with it) ${ }^{11}$ the coaching staff usually decide on training content, and coaches may not always be prepared to devote training time to preventive programmes. ${ }^{12}$ Thus, preventive measures proven highly efficacious in clinical trials do not necessarily work in real life on the football field. ${ }^{21} 22$ The measures have to be successfully implemented in the club, but if the players, staff and officials are not encouraged to use the measures, then the preventive efforts will fail. ${ }^{23}$ To progress to the field, practical tools are needed to bridge the gap between research and practice. ${ }^{21}$ In our experience, team physicians and other practitioners in the club medical teams are usually closely following the frontline of football medicine and are well informed about the latest research and any preventive measures. However, club medical staff may not always be able to influence all the factors contributing to injury. It is therefore important for them to work with players and coaches, CEOs, presidents and others in the club managerial staff, to obtain the support, participation and cooperation necessary for effective preventive actions.

There might be many obstacles to implementing preventive measures at club level. First, coaches may be concerned about a lack of football specificity or the validity of the suggested preventive measures from the club medical staff. For the modern coach, football specificity is essential, and many coaches want the training sessions to mimic matches in intensity and movement. Preventive measures involving exercises or movements not mimicking those in matches might therefore be less attractive for coaches.

Second, perceived lack of time might be another obstacle. Most professional clubs have a very congested playing calendar, ${ }^{18}$ with many matches as well as many days and nights of travelling. ${ }^{18}$ A tight schedule has a negative effect on the injury situation and the availability of players for training sessions, with increased muscle injury rates found in periods of match congestion. ${ }^{16}$ Consequently, coaches could be reluctant to include any time-consuming preventive measures in their regular training schedule. It is worth noting, however, that the 


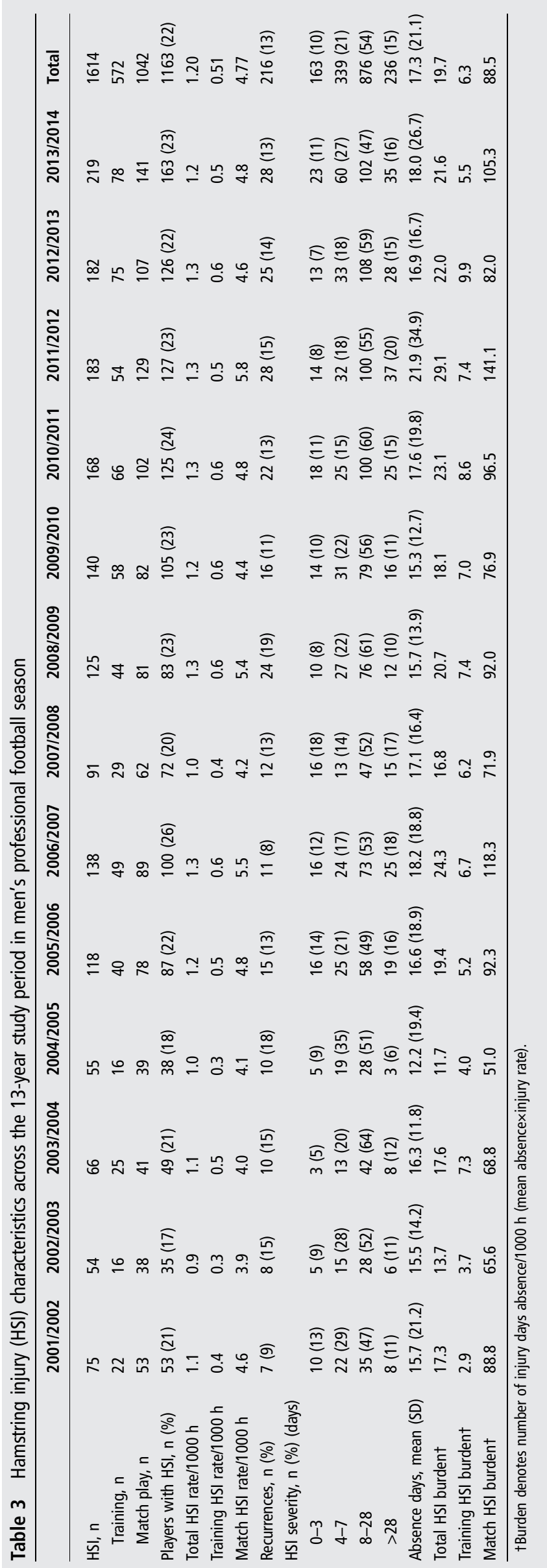

$\mathrm{NH}$ exercise, for instance, is to be carried out 1-2 times per week in the maintenance phase of the programme, ${ }^{9}{ }^{10}$ which would only take around $5 \mathrm{~min}$ from other practice.

Third, another obstacle might be negative opinions from players. Players could consider preventive training boring and may even report about side-effects such as muscle soreness. In their RCT of NH training, Petersen $e t a l^{8}$ described that most players in the intervention group initially experienced muscle soreness of the hamstrings. In our survey on adoption of the $\mathrm{NH}$ exercise in professional football, 6 of 50 participating clubs (12\%) reported 'many' or 'more than a few' complaints from players, and 12 (24\%) reported frequent coach complaints, respectively. ${ }^{12}$

\section{Targeting player factors-not enough for injury prevention?}

Most injury prevention programmes in football have addressed internal risk factors by providing players with exercises aimed at increasing person-related skills such as strength, balance, coordination and flexibility. ${ }^{5} 824-29$ There is currently good evidence that various neuromuscular training programmes can successfully reduce lower limb injuries among youth players. ${ }^{25}$ 28-30 Theoretically, such training programmes may have greater effect on youth players because these players are relatively less skilled and have not yet fully established their basic movement patterns. In contrast, professional senior footballers already perform to a high physical standard and additional non-football-specific (without the ball) physical training may not be as effective as it is in youth players.

External factors, such as player load and match frequency, might be important mechanisms underlying injuries. ${ }^{16}{ }^{17}$ The training load on players is traditionally decided by the coaching staff, whereas the long-term load, such as planning the season, promotional activities, etc, is normally decided by the board in cooperation with the coaching staff, but usually without influence from the medical staff. The overall training load is the sum of football training and fitness training. These two programmes are often run by different members of the coaching and fitness staff, and good internal communication is important to monitor and adapt the load on individual players. ${ }^{31}$

Other factors, such as consistency and the stability of the club in terms of coaching, medical staff and management, as well as the playing style of the team, could also be important external factors to consider in injury prevention. Therefore, decision makers (eg, coaches and managers) could play important roles in injury prevention and be decisive for the overall injury situation in a club. However, such external factors have not yet been evaluated in injury studies.

\section{Methodological considerations}

The main strength of this study is the substantial prospective data set obtained from a homogeneous group of male professional footballers. In addition, both the primary analysis, using linear regression with log-transformed injury rates as the dependent variable, and the 'sensitivity analysis', using a 2-year MA approach presented similar findings, indicate that the data set and the observed time trends are robust.

There are some limitations with the current study. First, the participating teams varied during the study period, with only a few teams participating in all 13 consecutive seasons. This means that a change in the included teams could affect the reported injury rates over the 13 -year period. The general time trends were, however, similar in a previous report between teams participating during the whole study period and the other teams making this effect less likely in the current study as 
-Injury burden —MA injury burden

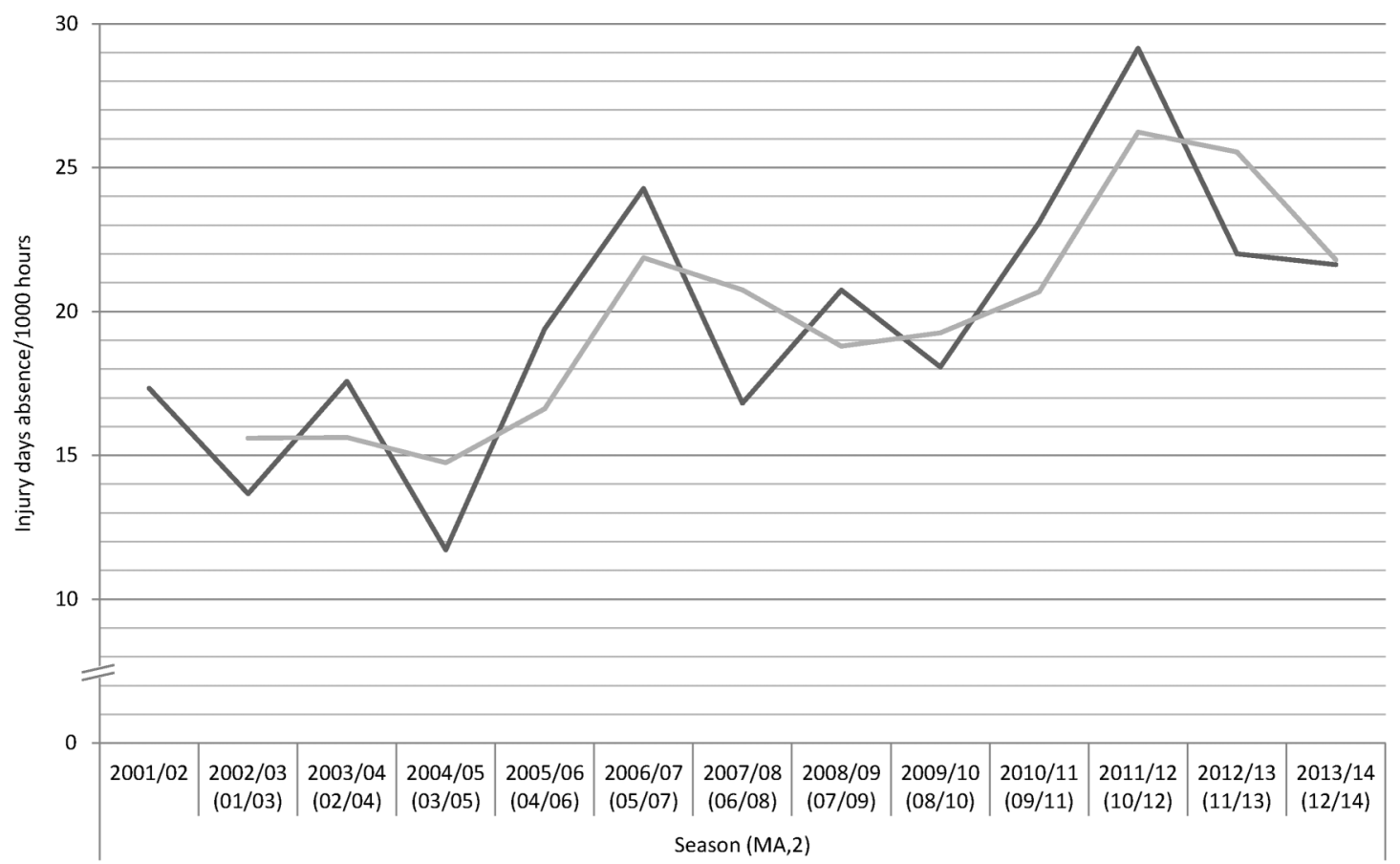

Figure 4 Time-trend analysis in hamstring injury burden (injury ratexmean absence per injury) showing a significant annual $4.1 \%$ increase over the 13-year period (black), and the moving average (MA) approach indicating a $4.0 \%$ yearly increase (grey). The Y-axis is not proportional.

well. ${ }^{12}$ Second, the clubs were not provided with any specific diagnostic criteria for hamstring injury and the data set therefore most probably comprises heterogeneous material of both structural and functional muscle injuries. ${ }^{32}$ Third, it is unclear whether the observed increased time-trend is true for all three hamstring muscles (biceps femoris, semitendinosus and semimembranosus), since this was not routinely specified in the injury reports during the first years of the study. ${ }^{20}$ Fourth, there

\section{What are the findings?}

- The training-related hamstring injury rate and injury burden in men's professional football players have increased substantially since 2001.

- The time-trend analyses showed an annual average $2.3 \%$ increase in the hamstring injury rate year over year and $4.1 \%$ increase in the total hamstring injury burden over the 13-year study period.

\section{How might it impact on clinical practice in the future?}

- Hamstring injury has been the single most common injury type in professional football for many years. The findings of increasing trend in injury rate are worrying, and prevention of hamstring injury should be given the highest priority.

- Factors such as player load, match frequency, playing style, team management, continuity of club medical and technical staff, etc, could be important underlying external risk factors for hamstring injury, and should be considered in future hamstring injury prevention initiatives and injury management. were no return-to-play criteria in our study manual, and it is therefore possible that the reported lay off time and reinjury frequency varied between clubs due to the different diagnostic and treatment algorithms.

A further limitation is that we only studied time trends and not the mechanisms behind the injuries. We have highlighted several likely mechanisms, but also appreciate that factors such as prolonged time before medical team give permission to return to play, or preventative lay off in case of minor symptoms, may play a role.

Acknowledgements The authors wish to thank all the participating clubs, including coaches, players and medical staff. Biostatistician Henrik Magnusson is acknowledged for planning and execution of the statistical analyses. They also thank Dr Ricard Pruna (HMO FC Barcelona), Dr Fabrizio Tencone (HMO Juventus FC), Dr Steve McNally (HMO Manchester United), Dr Rolf Timmermans (HMO PSV

Eindhoven) and Dr Nelson Puga (HMO FC Porto), for their contribution of expertise and experience from the field work of the participating clubs.

Contributors JE, MW and MH were responsible for the conception and design of the study. All the authors were involved in data collection over the study period. JE and $\mathrm{MH}$ conducted the analyses together with the biostatistician, and these were planned and checked by MW. All the authors contributed to interpretation of the findings and had full access to all data. JE wrote the first draft of the manuscript, which was critically revised by MW and MH. The final manuscript was approved by all the authors. JE is the study guarantor.

Funding The Football Research Group was established in Linköping, Sweden, in collaboration with Linköping University and through grants from the UEFA, the Swedish Football Association, the Football Association Premier League Limited and the Swedish National Centre for Research in Sports.

Competing interests None declared.

Patient consent Obtained.

Ethics approval The study design was approved by the UEFA Medical Committee and the UEFA Football Development Division.

Provenance and peer review Not commissioned; externally peer reviewed.

\section{REFERENCES}

1 Ekstrand J, Hägglund M, Waldén M. Epidemiology of muscle injuries in professional football (soccer). Am J Sports Med 2011;39:1226-32. 
2 Eirale C, Tol JL, Farooq A, et al. Low injury rate strongly correlates with team success in Qatari professional football. Br J Sports Med 2013;47:807-8.

3 Hägglund $M$, Waldén $M$, Magnusson $H$, et al. Injuries affect team performance negatively in professional football: an 11-year follow-up of the UEFA Champions League Injury Study. Br J Sports Med 2013;47:738-42.

4 Ekstrand J. Keeping your top players on the pitch: the key to football medicine at a professional level. Br J Sports Med 2013;47:723-4.

5 Arnason A, Andersen TE, Holme I, et al. Prevention of hamstring strains in elite soccer: an intervention study. Scand J Med Sci Sports 2008;18:40-8.

6 Askling C, Karlsson J, Thorstensson A. Hamstring injury occurrence in elite soccer players after preseason strength training with eccentric overload. Scand J Med Sci Sports 2003; 13:244-50.

7 Iga J, Fruer CS, Deighan $\mathrm{M}$, et al. 'Nordic' hamstrings exercise-engagement characteristics and training responses. Int J Sports Med 2012;33:1000-4.

8 Petersen J, Thorborg K, Nielsen MB, et al. Preventive effect of eccentric training on acute hamstring injuries in men's soccer: a cluster-randomized controlled trial. Am J Sports Med 2011;39:2296-303.

9 van der Horst N, Smits DW, Petersen J, et al. The preventive effect of the Nordic hamstring exercise on hamstring injuries in amateur soccer players: a randomized controlled trial. Am J Sports Med 2015;43:1316-23.

10 Goode AP, Reiman MP, Harris L, et al. Eccentric training for prevention of hamstring injuries may depend on intervention compliance: a systematic review and meta-analysis. Br J Sports Med 2015;49:349-56.

11 Bahr R, Thorborg K, Ekstrand J. Evidence-based hamstring injury prevention is not adopted by the majority of Champions League or Norwegian Premier League football teams: the Nordic Hamstring survey. Br J Sports Med 2015;49:1466-71.

12 Ekstrand J, Hägglund M, Kristenson $\mathrm{K}$, et al. Fewer ligament injuries but no preventive effect on muscle injuries and severe injuries: an 11-year follow-up of the UEFA Champions League Injury Study. Br J Sports Med 2013;47:732-7.

13 Fuller CW, Ekstrand J, Junge $A$, et al. Consensus statement on injury definitions and data collection procedures in studies of football (soccer) injuries. Br J Sports Med 2006:40:193-201.

14 Hägglund $M$, Waldén $M$, Bahr R, et al. Methods for epidemiological study of injuries to professional football players: developing the UEFA model. $\mathrm{Br}$ J Sports Med 2005;39:340-6.

15 Orchard J. Orchard Sports Injury Classification System (OSICS). Sports Health 1993:11:39-41.

16 Bengtsson $H$, Ekstrand J, Hägglund M. Muscle injury rates in professional football increase with fixture congestion: an 11-year follow-up of the UEFA Champions League Injury Study. Br J Sports Med 2013;47:743-7.

17 Dupont G, Nedelec M, McCall A, et al. Effect of 2 soccer matches in a week on physical performance and injury rate. Am J Sports Med 2010;38:1752-8.
18 Ekstrand J, Walden M, Hägglund M. A congested football calendar and the wellbeing of players: correlation between match exposure of European footballers before the World Cup 2002 and their injuries and performances during that World Cup. Br J Sports Med 2004;38:493-7.

19 Barnes C, Archer DT, Hogg B, et al. The evolution of physical and technical performance parameters in the English Premier League. Int I Sports Med 2014;35:1095-100.

20 Ekstrand J, Healy JC, Waldén $\mathrm{M}$, et al. Hamstring muscle injuries in professional football: the correlation of MRI findings with return to play. Br J Sports Med 2012;46:112-17

21 Verhagen $\mathrm{E}$, Voogt $\mathrm{N}$, Bruinsma $\mathrm{A}$, et al. A knowledge transfer scheme to bridge the gap between science and practice: an integration of existing research frameworks into a tool for practice. Br J Sports Med 2014;48:698-701.

22 ÓBrien J, Donaldson A, Finch C. It will take more than an existing exercise programme to prevent injury. Br J Sports Med 2016;50:264-5.

23 Finch C. A new framework for research leading to sports injury prevention. I SCi Med Sport 2006;9:3-9.

24 Emery CA, Meeuwisse WH. The effectiveness of a neuromuscular prevention strategy to reduce injuries in youth soccer: a cluster-randomised controlled trial. $\mathrm{Br}$ J Sports Med 2010;44:555-62.

25 Mandelbaum BR, Silvers HJ, Watanabe DS, et al. Effectiveness of a neuromuscular and proprioceptive training program in preventing anterior cruciate ligament injuries in female athletes: 2-year follow-up. Am J Sports Med 2005;33:1003-10.

26 Steffen $\mathrm{K}$, Myklebust G, Olsen OE, et al. Preventing injuries in female youth football -a cluster-randomized controlled trial. Scand J Med Sci Sports 2009;19:442-51.

27 van Beijsterveldt AM, Krist MR, Schmikli SL, et al. Effectiveness and cost-effectiveness of an injury prevention programme for adult male amateur soccer players: design of a cluster-randomised controlled trial. Inj Prev 2011;17:e2.

28 Waldén $\mathrm{M}$, Atroshi I, Magnusson $\mathrm{H}$, et al. Prevention of acute knee injuries in adolescent female football players: cluster randomised controlled trial. BMJ 2012:344:e3042.

29 Soligard T, Myklebust G, Steffen K, et al. Comprehensive warm-up programme to prevent injuries in young female footballers: cluster randomised controlled trial. BMJ 2008;337:a2469.

30 Kiani $A$, Hellquist $E$, Ahlqvist $K$, et al. Prevention of soccer-related knee injuries in teenaged girls. Arch Intern Med 2010;170:43-9.

31 Gabbett T. The training-injury prevention paradox: should athletes be training smarter and harder? Br J Sports Med 2016;50:273-80.

32 Müller-Wohlfahrt H, Hänsel L, Mithoefer K, et al. Terminology and classification of muscle injuries in sport: the Munich Consensus Statement. Br J Sports Med 2013:47:342-50 